
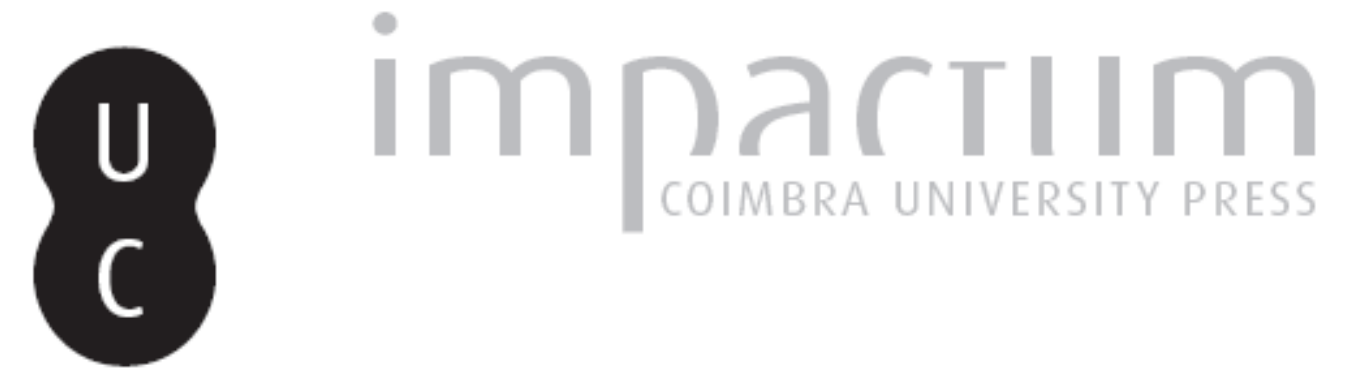

\title{
O fascínio da utopia: la città del Sole de Tommaso Campanella e a representação poético-filosófica da cidade
}

Autor(es): $\quad$ Ferro, Manuel

Publicado por: Faculdade de Letras da Universidade de Coimbra

URL persistente:

URI:http://hdl.handle.net/10316.2/32311

DOI:

DOI:http://dx.doi.org/10.14195/0870-4112_10_13

Accessed : $\quad$ 26-Apr-2023 10:14:12

A navegação consulta e descarregamento dos títulos inseridos nas Bibliotecas Digitais UC Digitalis, UC Pombalina e UC Impactum, pressupõem a aceitação plena e sem reservas dos Termos e Condições de Uso destas Bibliotecas Digitais, disponíveis em https://digitalis.uc.pt/pt-pt/termos.

Conforme exposto nos referidos Termos e Condições de Uso, o descarregamento de títulos de acesso restrito requer uma licença válida de autorização devendo o utilizador aceder ao(s) documento(s) a partir de um endereço de IP da instituição detentora da supramencionada licença.

Ao utilizador é apenas permitido o descarregamento para uso pessoal, pelo que o emprego do(s) título(s) descarregado(s) para outro fim, designadamente comercial, carece de autorização do respetivo autor ou editor da obra.

Na medida em que todas as obras da UC Digitalis se encontram protegidas pelo Código do Direito de Autor e Direitos Conexos e demais legislação aplicável, toda a cópia, parcial ou total, deste documento, nos casos em que é legalmente admitida, deverá conter ou fazer-se acompanhar por este aviso.

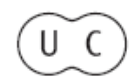



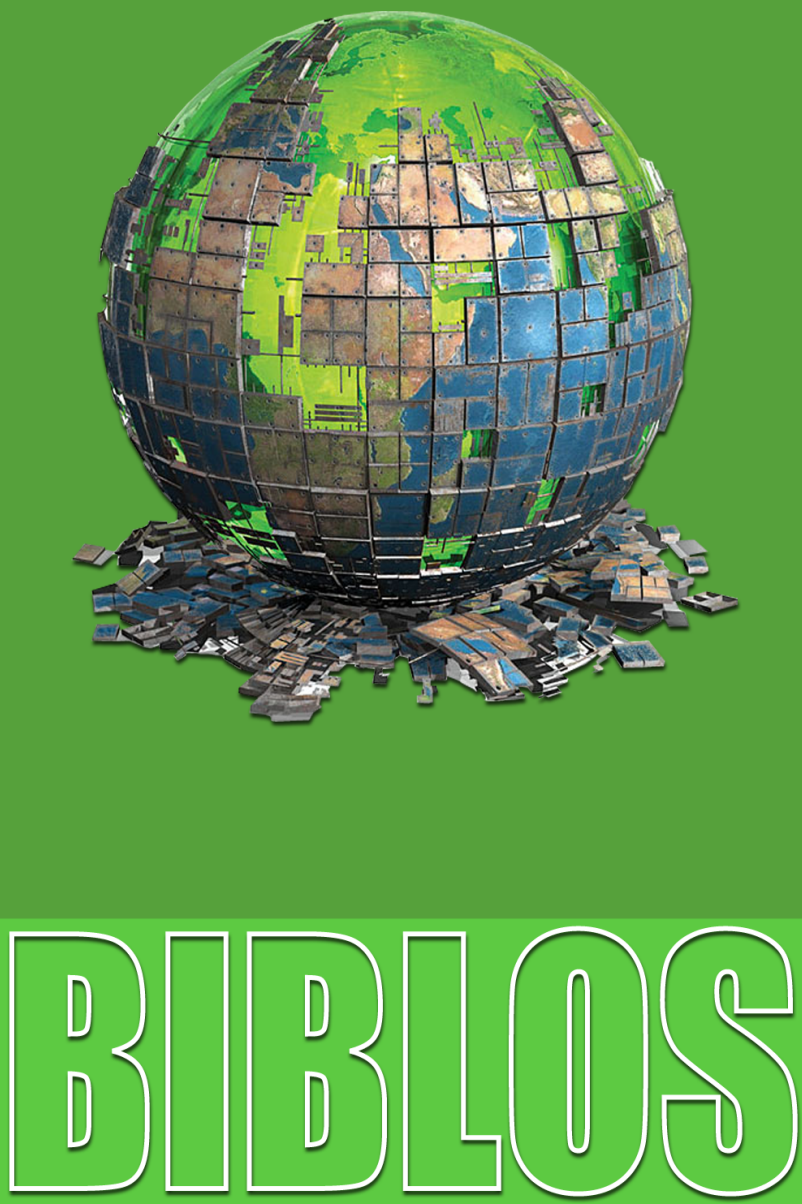

$\frac{\text { REVISTA DA FACULDADE DE LETRAS }}{\text { UNIVERSIDADE DE COIMBRA }}$ 
Biblos, n. s. X (2012) $\ldots-\ldots$

Manuel Ferro

Faculdade de Letras da Universidade de Coimbra

\section{O FASCÍNIO DA UTOPIA: LA CITTÀ DEL SOLE DE TOMMASO CAMPANELLA E A REPRESENTAÇÃO POÉTICO-FILOSÓFICA DA CIDADE}

\section{Resumo}

Inserida num filão literário secular em que a celebração da cidade em termos encomiásticos enaltece a vida quotidiana, cívica e religiosa de centros urbanos existentes, La Città del Sole, de Tommaso Campanella, contrapõe um projecto teocrático universal fundado na religião natural, regido por princípios racionais rigorosos e viabilizado por um conselho de sábios-sumo sacerdotes. Para além do lugar de relevo que ocupa no âmbito do pensamento político do século XVII,é um marco no campo da expressão utópica da cidade-estado ideal, manifestação do alento místico e profético do autor, em coerência e em estreita relação com as crenças escatológicas, em que acreditava entusiasticamente. Depositando uma fé inabalável na missão providencial de iluminação e intervenção que lhe cabia na instauração de um novo modelo de relações entre os homens, a instituir no futuro, Campanella considerava ser chegado o momento da renovação, do restabelecimento da Idade do Ouro, de uma nova era que se deveria iniciar mediante um vasto movimento de insurreição contra o status quo vigente e implicava uma reorganização total, quer a nível político, quer social. A miragem da cidade feliz, do amor e da concórdia, em que o egoísmo é superado por valores mais elevados, como o bem comum, associa-se ao carácter exemplar da orgânica da pólis, mediante a notável organização do trabalho e o sentido do dever cumprido. Conciliando os seus ideais com a realidade contingente, projecta-se aqui um novo modelo de cidade, ao tentar articular a substância utópica e os sonhos de renovação político-social do autor com aspectos, por vezes, ortodoxos, numa obra marcada, sem dúvida alguma, pela exuberância, rebeldia e inquietude, que virá a marcar a produção utópica dos séculos vindouros e a deixar marcas até à actualidade.

Palavras-Chave: Utopia, Tommaso Campanella, Cidade.

\footnotetext{
Abstract

Inserted in a several centuries old literary tradition in which the celebration of the town in encomiastic terms exalts the daily, civic and religious life of
} 
the existing urban centers, La Città del Sole (The Sun City), by Tommaso Campanella, counterpoints an universal theocratic project based on a natural religion, ruled by strict rational principles and made viable by a council constituted by wise high priests. Besides the importance it holds within the field of the 17.th century political thought, it stands as a reference in the sphere of the utopian expression of the ideal city-state, revelation of the mystical and prophetic capability of the author, in coherence and in strict relation with the eschatological believes, in which he trusted such an enthusiastic faith. Relying such a steady belief upon the providential mission of the enlightenment and the intervention that fitted him in the instauration of a new pattern of relations among mankind, to be established in future, Campanella considered that the moment of that spiritual renewal had arrived, a kind of reinstitution of the Golden Age, of a new era, which should be started with a total reorganization, either at a political, or at a social level. The mirage of a happy town, of love and harmony, in which selfishness is overcome by higher values, such as common wellbeing, is connected to the exemplary character of the polis arrangement, through a remarkable organization of work and the sense of the fulfilled duty. Conciliating its ideals with contingent reality, a new model of town is so outlined, trying to join the utopian substance and the dreams of social and political renewal of the author with aspects sometimes orthodox in a work marked, without any doubt, by exuberance, stubbornness and inquietude, that will identify the utopian production for the centuries to come, leaving tracks up to modern times.

Keywords: Utopia, Tommaso Campanella, Town. 
Na esteira de um subgénero literário com larga tradição, muito embora renascido com novo fulgor graças à acção dos humanistas, o das laudes urbium, ou elogio das cidades, inserida no género epidíctico ${ }^{1}$, La Città del Sole ${ }^{2}$, de Tommaso Campanella, assume uma importância determinante no contexto das letras italianas por nela se cruzarem outros vectores que a distinguem e enriquecem perante a restante produção literária dessa categoria. Não se centrando exclusivamente na realidade observada, a cidade é aí repensada; projecta-se no campo da utopia, abrindo espaço à apresentação de aspectos que permitiriam a concepção e planeamento de uma cidade ideal. Por outro lado, será igualmente de ter em conta que La Città del Sole compreende a resposta do pensador às instâncias e exigências histórico-políticas e sociais da sua própria época. Todavia, a aproximação proposta à tradição literária dos elogios de cidades justifica-se pelo facto de seguir na generalidade a estrutura, os temas e os tópicos que conformam tal modelo.

Segundo Aires A. Nascimento, "no fim do século III, o retor Menandro coloca o elogio da pátria e da cidade à testa das diferentes formas do discurso epidíctico (nada menos que vinte e três); entre os tópicos a ter em conta considera: situação, qualidade de clima, produtos da terra, origem, fundadores, forma de governo, história, destaque nas ciências e nas letras, celebrações festivas, monumentos e outros motivos de atracção" 3 . Se desde a Antiguidade esta forma literária se viera afirmando, ao longo da Idade Média, enriquece-se com composições como o Liber Pergaminus, de Mosé di Bergamo, da primeira metade do século XII, ou, sobretudo, com as laudes Romae, como atesta a obra intitulada Mirabilia Romae, de cerca de 1150, em que à descrição da

1 Sobre esta matéria, veja-se Aires A. Nascimento, “Apresentação”, pp. 57-58 e 60-61, a Damião de Góis, Elogio da Cidade de Lisboa. Vrbis Olisiponis Descriptio, Lisboa, Guimarães Editores, 2002, pp. 43-72; Walz, Rhetores Graeci, IX, 127-330; Spengel, Rhetores Graeci, III, 331-446; Theodore C. Burgess, "Epideictic Literature", in: Studies in classical Philology, Chicago, III, 1902, pp. 89-148; J. K. Hyde, "Medieval Descriptions of Cities", in: Bulletin of the John Rylands Library, 48, 1966, pp. 308-340; Gina Fasoli, "La coscienza civica delle 'Laudes civitatum", in: La coscienza cittadina nei comuni italiani del Duecento. Atti dell' XI Convegno del Centro di Studi sulla spiritualità medievale, Todi, Academia Tudertina, 1972, pp. 9-44.

2 Tommaso Campanella, La Città del Sole, Milano, Mondadori, 1991 (Frankfurt am Main, por Tobia Adami, 1623, embora redigida em 1602).

3 Aires A. Nascimento, “Apresentação", loc. cit., p. 58. 
cidade se associam lendas romanas ${ }^{4}$. Mais tardiamente, as crónicas urbanas inserem-se neste filão, ao testemunharem a celebração dos momentos de maior esplendor das cidades, o orgulho dos 'burgueses' e o amor dos novos cidadãos pelas maravilhas da sua terra: Bonvesin de la Riva, por exemplo, em De magnalibus urbis Mediolani ${ }^{5}$, enaltece a opulência da vida quotidiana, cívica e religiosa de Milão; um anónimo genovês exalta poeticamente a sua cidade ${ }^{6}$; Martin da Canal elogia a cidade da laguna numa crónica iniciada em 1267 e interrompida em 1275, a Storia di Venezia ${ }^{7}$, em franco-véneto; Giovanni Villani compõe a Nuova $\mathrm{Cronica}^{8}$, centrada na cidade de Florença, obra que foi continuada, primeiro, pelo irmão Matteo e, depois, pelo filho Filippo ${ }^{9}$. A todas elas é comum o uso do discurso hiperbólico em função do entusiasmo sentido pelos autores, visando o engrandecimento e a glorificação da cidade em que vivem.

Contudo, no Renascimento, tendo em conta o acentuado orgulho pelo torrão natal, reforçado por uma nova consciência política e cívica, bem como pela ideia de imitar os Antigos e mostrar a sua superação pelos modernos em riqueza e sabedoria, o elogio das cidades alcança maior vitalidade e surgem numerosos textos com esse objectivo explícito ou, então, outros acabam por ser contaminados pelo mesmo espírito, muito embora redigidos com diferentes finalidades. Com a divulgação de modelos literários de cidades e estados exemplares, como a República, de Platão, a ideia da cidade-estado italiana é vista como o grau de desenvolvimento dessa realidade mais perfeito até então alcançado. Por outro lado, o engrandecimento da urbe mediante a construção de edifícios grandiosos torna-se motivo de orgulho não só

4 Cf. Luigi Salvatorelli, "Arti e lettere nella Prima metà del secolo XIII", p. 166, in: Luigi Salvatorelli, Sommario della Storia d'Italia, Torino, Einaudi, ${ }^{12} 1969$, pp. 163-166.

5 Bonvesin de la Riva, Le meraviglie di Milano, a cura di M. Corti, Milano, Bompiani, 1974.

6 Anonimo genovese, Poesie, a cura di L. Cocito, Roma, Ateneo, 1970, pp. 560-563.

7 Martin da Canal, Les estoires de Venice, cronaca veneziana in lingua francese dalle origini al 1275, trad. it. di A. Limentani, Firenze, Olschki, 1972.

8 Giovanni Villani, Nuova Cronica, Vol. I-III, Milano, Guanda, 1991.

9 Sobre esta matéria, veja-se Remo Ceserani e Lidia de Federicis, Il Materiale e l'Immaginario. Vol. 3: La Società Urbana, Torino, Loescher Editore, 1979, pp. $70-88$. 
para o cidadão, como para as respectivas instituições. Não é por acaso que, em muitos casos, a iniciativa desse florescimento arquitectónico e urbano se deve aos governantes - os Médicis em Florença, os papas em Roma, os Duques em Ferrara nas suas cidades...

Os grandes artistas são, então, encarregados do traçado das novas cidades e estabelece-se, deste modo, uma estreita ligação entre as artes, particularmente a arquitectura, e a política. Delineiam-se cidades ideais, como Sforzinda, projectada por Filarete, que obedecem a critérios de dignidade, ordem, higiene, funcionalidade e beleza, como Leonardo da Vinci propõe. Trata-se, assim, da construção de um cosmos em que o homem se insere harmoniosamente e para o qual contribui o concurso de todos os ramos do saber, numa verdadeira rede de interdisciplinaridade entre ciências, artes, poesia, moral e política. A fé e o optimismo que se deposita nas capacidades do homem, juntamente com a defesa da sua dignidade e a sede de saber, que se exprime, baconianamente, na possibilidade de domínio das forças da natureza; a aspiração à legalidade em que assenta a crítica das instituições e leva a enfrentar a violência e a fraqueza das estruturas sociais vigentes; a rejeição das superstições em nome da razão, para a qual se reivindica a autonomia, diante do autoritarismo dos dogmas: tudo isto constitui a herança do Renascimento que se propõe e se reequaciona perante a situação de crise que o século XVII enfrenta, proporcionando, assim, o aparecimento de imagens de sociedades harmoniosas, eficientes e funcionais ${ }^{10}$.

Não admira que seja neste contexto que as utopias florescem. Thomas More $^{l l}$ localiza, na altura, a cidade ideal numa ilha maravilhosa, superiormente planificada e com um nível e estilo de vida invejável para o europeu daquela época. Aí se esboçam as actividades - artes e ofícios - que ocupam a população, a estrutura social, as relações entre os cidadãos, a educação dos jovens, a vida comunitária, o regime de bens, a prática da guerra e razões que a justificam e a vivência religiosa, tudo gerido à luz da razão, que permite a existência de uma sociedade humanamente perfeita. Tal obra vem fazer desabrochar

${ }^{10}$ Cf. Franco Mollia, "Utopia ierocratica", p. 50, in Tommaso Campanella, La Città del Sole, loc. cit., pp. 48-54.

11 Thomas More, De optimu reipublicae statu deque nova insula Utopia libellus vere aureus, Louvain, Arte Theodorici Martin, 1516. 
uma série de outras afins, entre as quais se contam A Nova Atlântida ${ }^{I 2}$, de Francis Bacon, e, depois, La Città del Sole, que recuperam, por sua vez também, o mito da Atlântida e se desenrolam em ilhas mais ou menos paradisíacas. Aí crescem cidades exemplares e civilizações modelares, quer devido ao isolamento que o espaço insular permite, quer simultaneamente pelo facto de as ilhas serem simultaneamente pontos de abrigo, contacto e intercâmbio de culturas.

A utopia emergente impõe-se, assim, por contestar igualmente o presente; da crítica social passa à invenção; fundamenta-se numa sociedade em que a imaginação ocupa o poder e confia na natureza humana, valorizando a capacidade de organização humana. Racionalista, planifica e reforma a cidade, que reproduz por sua vez a ordem natural do universo. Ao prever a educação de cada cidadão, liberta-o ao mesmo tempo da infelicidade que o pode assolar no quotidiano, porventura causada pela propriedade privada ${ }^{13}$.

Estruturada sob a forma de um diálogo estabelecido entre o Grão-Mestre da Ordem dos Hospitalários de S. João de Jerusalém e um Almirante genovês, seu hóspede, outrora piloto de Colombo, a Cidade do Sol é apresentada como um lugar feliz, ordenado por leis e costumes que consubstanciam a ideia de uma república filosófica ${ }^{14}$.

Situada na ilha de Taprobana (Ceilão, ou porventura, Sumatra), reproduz o antigo mito de Atlântida, descrito por Platão no Timeu e no Crítias, bem como o das ilhas felizes, de Horácio, na esteira de Hesíodo, questionando na época das descobertas marítimas a localização fantástica do paraíso terrestre ${ }^{15}$.

À semelhança de Thomas More, à medida que se apresentam as características da cidade e sua organização, suscita-se desse modo a

${ }^{12}$ Francis Bacon, Sylva sylvarum: or a Naturall Historie. In ten centuries... [The New Atlantis], London, J. H. [John Haviland], for William Lee, 1627.

${ }_{13}$ Sobre a reflexão centrada nas questões relacionadas com a utopia, veja-se Fátima Vieira (Org.), Saberes Partilhados. O Lugar da Utopia na Cultura Portuguesa, Vila Nova de Famalicão, Edições Quasi, 2006; Maria de Fátima Silva (Coord.), Utopias e Distopias, Coimbra, Imprensa da Universidade, 2009; José Mattoso, "A morte das utopias e o fim da História", in Levantar o Céu. Os labirintos da Sabedoria, Lisboa, Temas e Saberes/Círculo de Leitores, 2012, pp. 61-74.

${ }^{14}$ Tommaso Campanella, op. cit, p. 55.

${ }^{15}$ Cf. Franco Mollia, op. cit., p. 50-51. 
reflexão do leitor e evidenciam-se as contradições existentes perante a actualidade político-social vigente. Campanella propõe deste modo a abertura de um caminho para o progresso da sociedade, mediante um modelo que exclui o erro, a aventura e até a liberdade - apesar de esta ser entendida como um dos factores de dinamismo social. Se a descrição inicial das muralhas pode eventualmente sugerir a ideia de uma prisão modelar, o aproveitamento que delas se faz remete para avançados métodos de ensino e aprendizagem fundados na componente audiovisual ${ }^{16}$. Não obstante, a passividade dominante da população concilia-se com os pormenores reguladores do funcionamento do todo social. A estrutura rigidamente hierárquica e hierática reflecte-se na organização administrativa vigente, que impõe a importância da ordem interna da cidade como princípio prevalecente sobre todo e qualquer anseio humano individual.

Mais fantasiosa que o modelo de More, a Cidade do Sol estabelece um protótipo de sociedade também mais contestatário. No que se prende com a organização social, o conceito tradicional de família desaparece: as crianças são concebidas segundo as melhores regras da eugenia e da astrologia conhecidas e educadas em comum ${ }^{17}$. A vivência amorosa é reconhecida, mas está absolutamente separada da função reprodutora ${ }^{18}$.

Para a nova sociedade, defende-se, por conseguinte, um molde de educação inovador. As crianças adquirem os conhecimentos indispensáveis seguindo as explicações e comentários de mestres doutos, que acompanham a contemplação das imagens disponíveis nos sete muros concêntricos das fortificações da cidade, cujos acessos, por sua vez, se dispõem de acordo com a orientação dos pontos cardeais. Os métodos de ensino são tão avançados que as crianças aprendem num ano os conteúdos que nas escolas do Velho Mundo demora dez ou quinze anos de estudo ${ }^{19}$.

Todos os solarianos trabalham, já que a ociosidade e a vagabundagem explicam o empobrecimento da sociedade tradicional. O horário de quatro horas de trabalho nos campos assegura a subsistência de todos ${ }^{20}$.

\footnotetext{
16 Tommaso Campanella, op. cit, pp. 55-56 e 58-61.

${ }^{17}$ Idem, ibidem, pp. 61 e 62.

${ }^{18}$ Idem, ibidem, pp. 68-72.

${ }^{19}$ Idem, ibidem, pp. 64-66.

${ }^{20}$ Idem, ibidem, pp. 73-74.
} 
Contudo, inovações técnicas aliviam o labor quotidiano. Às velhas charruas aplicam-se velas para aproveitar a força motriz do vento, por exemplo ${ }^{21}$. Constroem carros à vela, barcos sem remos, nem velas, que, apesar de tudo, se deslocam ${ }^{22}$. Recorrem à magia para facilitar os trabalhos agrícolas e fazer frutificar os solos, a que juntam a atenta consulta de textos, como as Geórgicas e as Bucólicas ${ }^{23}$. Alimentam-se de carne e legumes, segundo normas dietéticas precisas ${ }^{24}$. $\mathrm{O}$ dinheiro é suprimido internamente e apenas usado em casos excepcionais, como nos contactos e trocas comerciais com estrangeiros ${ }^{25}$.

Organicamente, a sociedade é rigidamente hierarquizada. Acima de tudo e de todos, reina o Metafísico, que dispõe de poder absoluto no plano espiritual e temporal, e é coadjuvado por três magistrados com designações sugestivas: Sabedoria / Sir, ocupa-se com matérias relacionadas com as artes liberais e mecânicas; Poder / Pon regula as questões relacionadas com a paz e a guerra; Amor / Mor trata das matérias ligadas às sementeiras e reprodução quer animal, quer da população, instituindo regras precisas para a sua consecução ${ }^{26}$.

A população idosa é valorizada não só pelo aconselhamento que proporciona à juventude, como pelos ensinamentos e educação dos mais pequenos, além de assumir alguns cargos de coordenação e chefia ${ }^{27}$.

Em termos religiosos, apesar da existência de rituais públicos de culto em que participa toda a população, a religião é fundamentalmente racional, consistindo na crença num Ser Supremo, Providencial e Criador, rodeado de um panteão ecléctico de figuras oriundas das mais diversas proveniências, desde a mitologia greco-latina ao Cristianismo, ao Islamismo e a crenças orientais. O Sol e as estrelas são venerados por serem considerados o rosto da divindade. Um sistema eficaz de confissão

${ }^{21}$ Idem, ibidem, p. 82.

${ }^{22}$ Idem, ibidem, p. 83; Cf. Franco Mollia, "Fabricare una città mirabile”, p. 46, in Tommaso Campanella, La Città del Sole, loc. cit., pp. 45-48.

${ }^{23}$ Idem, ibidem, p. 82; Cf. Franco Mollia, "Fabricare una città mirabile", loc. cit., p. 46.

${ }^{24}$ Tommaso Campanella, op . cit, pp. 83-85.

25 Idem, ibidem, p. 81; Cf. Franco Mollia, "Fabricare una città mirabile", loc. cit., p. 48.

${ }^{26}$ Idem, ibidem, pp. 58-59; Cf. Franco Mollia, "Fabricare una città mirabile", loc. cit., p. 46.

${ }^{27}$ Idem, ibidem, pp. 63 e 66-67. 
dos pecados permite fazer o controlo da população e a economia da polícia. Cada um confessa as suas faltas ao chefe de bairro, que, por sua vez, se confessa a um magistrado e, assim, se sobe na hierarquia até ao Metafísico. Este, sabendo de tudo e dos problemas que afectam os solarianos, dá solução às faltas mais prementes da cidade. Assim se afastam os perigos que poderão afectar o eficaz funcionamento da cidade, permitindo uma vivência feliz e plena em comunidade ${ }^{28}$.

Praticam ritos apotropaicos, a fim de satisfazerem a dívida de todos perante a divindade, bem como rituais mágico-religiosos ${ }^{29}$. Pelo facto de acreditarem na imortalidade da $\mathrm{alma}^{30}$, e apesar de aceitarem o princípio da metempsicose em condições especiais ${ }^{31}$, recorrem à cremação dos cadáveres ${ }^{32}$. Praticam a dissecação dos corpos em condenados à morte, para fins de estudo de anatomia ${ }^{33}$. Em contrapartida, reconhecem como excepcionais as pessoas atingidas pela epilepsia, o "morbo sacro", por o consideraram sinal de grande inteligência ${ }^{34}$.

Para que não sejam acometidos pelo egoísmo ou desejo de posse da propriedade privada, mudam de habitação de seis em seis meses ${ }^{35}$. Nos hábitos do quotidiano, as refeições são tomadas em comum, escutando boas leituras e música deleitosas ${ }^{36}$.

Dominam os conhecimentos mais actuais, apreciam as descobertas do tempo, como a imprensa e as notícias da existência de mundos novos, a saber, as terras desconhecidas até ao momento ${ }^{37}$. Pelo facto, Copérnico é colocado ao nível dos grandes benfeitores da Humanidade. Inventaram a arte de se elevarem nos ares, conhecem o fogo-de-artifício, utilizam telescópios para a observação das estrelas, e aguardam com expectativa a descoberta de trombetas acústicas para escutarem a harmonia da música celeste das esferas ${ }^{38}$.

${ }^{28}$ Idem, ibidem, pp. 90-96.

${ }^{29}$ Idem, ibidem, p. 90; Cf. Franco Mollia, "Fabricare una città mirabile", loc. cit., p. 47.

${ }^{30}$ Idem, ibidem, p. 95.

${ }^{31}$ Idem, ibidem, pp. 75-76.

${ }^{32}$ Idem, ibidem, p. 92.

${ }^{33}$ Idem, ibidem, p. 97.

${ }^{34}$ Idem, ibidem, p. 86.

${ }^{35}$ Idem, ibidem, p. 66.

${ }^{36}$ Idem, ibidem, pp. 66-68.

${ }^{37}$ Idem, ibidem, p. 60.

${ }^{38}$ Idem, ibidem, pp. 98-99. 
Em caso de ataque, defendem-se com a participação de toda a população. Em campo de guerra, ainda se dispõem em duas alas com forma de chifres e seguem a técnica do quadrado, como os Romanos, na construção dos acampamentos, embora já se encontrem apetrechados com pistolas e outras peças de artilharia ${ }^{39}$. As mulheres têm idêntica formação militar para intervirem igualmente em combate ${ }^{40}$. São pacíficos, mas apreciam artes marciais e ocupações fatigantes, como o desporto, particularmente a natação, a caça e a navegação $0^{41}$.

O sistema judicial é radical: punem com a pena de morte o homicida. Os estrangeiros são vigiados e não existem prisões $^{42}$.

Enfim, com todos estes requisitos, dir-se-ia que a Cidade do Sol pressupunha uma sociedade perfeita, organicamente estruturada, em que a prática política assentava sobre uma base moral, que, por sua vez, era fundada em princípios naturais. Tratar-se-ia de uma cidade disciplinada, onde cada um teria um papel definido e cada gesto seria bem coordenado com os demais ${ }^{43}$. A relação entre o microcosmos / Homem e o macrocosmos / Cidade surge como a de uma unidade harmoniosa, em que se articulam dois planos do mesmo universo em simbiose ${ }^{44}$. O programa político apontado era, sem dúvida alguma, idealizado para construir a cidade dos novos tempos, que se sobreporia à dura realidade do seu tempo, particularmente a que Campanella conhecia, do Sul de Itália. Em contraponto, esboça-se, então, um sistema de comunismo aristocrático, sugerido por leituras de autores clássicos, como Platão, e pelo domínio de outras lendas e narrativas da tradição medieval, como a das ilhas dos bem-aventurados e dos sonhos, situadas nos antípodas da Terra. Quase se trata de uma tentativa de retorno à Idade do Ouro, uma fábula arcádica bem radicada nas espectativas de

${ }^{39}$ Idem, ibidem, p. 77.

${ }^{40}$ Idem, ibidem, p. 75 e 78.

${ }^{41}$ Idem, ibidem, p. 80.

${ }^{42}$ Idem, ibidem, pp. 88-89.

${ }^{43}$ Cf. Giorgio Barberi Squarotti, "La Città del Sole", in Literatura Italiana. Linhas-Problemas-Autores, São Paulo, Nova Stella-Istituto Italiano di Cultura-EDUSP, 1989, p. 318; e Giulio Ferroni, Profilo Storico della Letteratura Italiana, Volume I, Milano, Einaudi Scuola, 2006, pp. 436-437.

${ }^{44}$ Cf. Franco Mollia, "Introduzione", p. 9, a Tommaso Campanella, La Città del Sole, loc. cit., pp. 5-40. 
renovação civil e política do século ${ }^{45}$. Ou então, mais uma visão do país da Cuccagna, em que se repetem os arquétipos do Éden e se profetiza o advento de reinos milenários, com aspirações a acontecimentos admiráveis. Daí o aproveitamento de sugestões simbólicas de carácter espiritualista, da concepção trinitária e escatológica, bem como do pensamento hermético, expressas nas exegeses místicas de um Gioacchino da Fiore, associadas ainda a pistas do campo da magia e da tradição profética medieval ${ }^{46}$. Não é por acaso também que essa é a época de arranque para a divulgação do mito do Quinto Império! Contudo, para a proposta renovação do contexto alimentado pelo milenarismo de algum modo apocalíptico, apontam-se os instrumentos e engenhos habilmente engendrados ou teorizados por um saber de marca experimental, que prenuncia a abertura e afirmação do primado da ciência, a desenvolver-se posteriormente. Por isso se pressente nas entrelinhas uma fé optimista no Homem e na sede de saber, na sua competência, apesar de se reconhecerem as suas fraquezas. Apela-se, por consequência, para nomes como Bacon, Descartes, Galileo, Mersenne, Gassendi, que fundavam o poder do engenho humano no domínio racional das relações entre os elementos e as forças da natureza mediante o conhecimentos das causas e efeitos para se chegar a conclusões infinitas, profundas e admiráveis ${ }^{47}$.

Não obstante todos estes aspectos, a Cidade do Sol não será propriamente uma sociedade plenamente feliz; pressente-se a tensão entre o indivíduo e a comunidade, e a renúncia à liberdade individual torna-se um factor sintomático determinante ${ }^{48}$. Ocasionalmente, se se rejeitam as superstições em nome da razão, procede-se ainda à apologia da magia e astrologia para suporte de alguns dogmas. Sinais dos tempos e contradições que atravessam toda a obra de Campanella!!!...

45 Cf. Mario Sansone, Storia della Letteratura Italiana, Milano, Principato Editore, 1962, p. 280, e Natalino Sapegno, Compendio di Storia della Letteratura Italiana. Volume: Cinquecento, Seicento, Settecento, Firenze, La Nuova Italia Editrice, 1983, pp. 220-224.

${ }^{46}$ Cf. Mario Sansone, op. cit., p. 280; e Giulio Ferroni, Storia della Letteratura Italiana. Vol. 2. Dal Cinquecento al Settecento, Milano, Einaudi Scuola, 2008, p. 310 .

${ }^{47}$ Cf. Giulio Ferroni, Storia della Letteratura Italiana. Vol. 2. Dal Cinquecento al Settecento, loc. cit., p. 314.

${ }^{48}$ Cf. Franco Mollia, p. "Utopia ierocratica", loc. cit., 48. 
A culminar tudo isso, assistimos à apologia de um regime hierocrático e totalitário ${ }^{49}$.

Assim, se Campanella parece, por um lado, um retardatário, um epígono renascentista nalguns aspectos, por outro, reflecte a crise dominante no seu tempo e denuncia já premissas das conquistas científicas do Seicento e ainda do Settecento.

O certo é que La Città del Sole é a resposta, sem dúvida polémica, a uma realidade que a época patenteava, marcada por guerras, miséria, desespero, epidemias, arbitrariedades de príncipes maquiavélicos, que faziam cair sobre os povos todos as consequências da sua prepotência, em nome da "razão de Estado". O descontentamento grassava; a insegurança era geral, com os assaltos constantes dos Turcos. Nos espaços siderais, eclipses e outros fenómenos prenunciavam inebriantes presságios. Desta confusa ebulição de intuições e superstições, emerge um anseio de legalidade, justiça e estabilidade na visão da cidade e do Estado, muito embora ainda enquanto fundamento teórico, que permite uma abordagem crítica à violência reinante e a denúncia das instituições sociais e políticas obsoletas ${ }^{50}$. Por isso, para além das suspeitas de heresia e rebelião política, Campanella é acusado de envolvimento na revolta de 1599 , contra o domínio espanhol na Calábria ${ }^{51}$. Apontado como seu principal instigador, decerto contaria fazer daquela região uma República, para a qual elabora um programa, um sonho de um estado teocrático ${ }^{52}$, que depois plasma nas páginas de La Città del Sole.

Protegido e simultaneamente contestado por papas, reis e políticos, rebatido por Descartes, foi igualmente tido como louco, facínora, astuto e extravagante ${ }^{53}$. Segregado vinte e sete anos nos cárceres de

${ }^{49}$ Cf. Franco Mollia, "Introdução", loc. cit., p. 17.

${ }^{50}$ Cf. Remo Ceserani e Lidia de Federicis, op. cit., pp. 765-766; e Luigi Firpo, "La personalità di Tommaso Campanela", in G. Bruno - T. Campanella, Scritti Scelti, a cura di Luigi Firpo, Torino, UTET, 1949, pp. 13-14 e 21-24 (também inserido em Riccardo Bruscagli, Lanfranco Caretti e Giorgio Luti, Letteratura Italiana Con Saggi Critici, Tomo Secondo: Dal Cinquecento al Settecento, Milano, Mursia, 1994, pp. 474-476.

${ }^{51}$ Cf. Remo Ceserani e Lidia de Federicis, op. cit., p. 340; e Franco Mollia, loc. cit., p. 469

52 Sobre esta matéria, leia-se igualmente o soneto "Non è re chi ha regno, ma chi sa regere", in Remo Ceserani e Lidia de Federicis, op. cit., pp. 766-767.

${ }^{53}$ Cf. idem, ibidem, pp. 346-347. 
Nápoles, mais três nas prisões do Santo Ofício em Roma, no silêncio e no esquecimento da cela legou aos vindouros uma das mais belas representações poético-filosóficas da cidade dos homens ${ }^{54}$. Não admira que a sua memória tenha sido revalorizada nas utopias do século XIX e aspectos por ele enunciados tenham sido recuperados e amplamente aprofundados, inspirando ainda reivindicações das gerações mais próximas dos nossos dias.

\section{Bibliografia:}

CAMPANELlA, Tommaso, La Città del Sole e altri scritti, Milano, Arnoldo Mondadori, 1991.

CESERANI, Remo e DE FEDERICIS, Lidia, Il Reale e l'Immaginario. Vol. 5: La Società dell'Antico Regime, Torino, Loescher Editore, 1980.

FERRO, Manuel, “A Celebração Épica da Fundação da Cidade: Vila Rica, de Cláudio Manuel da Costa", in Biblos, n. s., IV (2006), pp. 201-233.

FERRONI, Giulio, Profilo Storico della Letteratura Italiana, Volume I, Milano, Einaudi Scuola, 2006.

FERRONI, Giulio, Storia della Letteratura Italiana. Vol.2. Dal Cinquecento al Settecento, Milano, Einaudi Scuola, 2008.

FIRPO, Luigi, "La personalità di Tommaso Campanela", in G. Bruno T. Campanella, Scritti Scelti, a cura di Luigi Firpo, Torino, UTET, 1949, pp. 13-14 e 21-24 (também inserido em BRUSCAGLI, Riccardo; CARETTI, Lanfranco e LUTI, Giorgio, Letteratura Italiana Con Saggi Critici, Tomo Secondo: Dal Cinquecento al Settecento, Milano, Mursia, 1994, pp. 474-476).

FRAUENFELDER, Elisa, Il fascino dell'utopia pedagogiva. «La Città del Sole», Napoli, Liguori, 2005.

MATTOSO, José, “A morte das utopias e o fim da História”, in Levantar o Céu. Os labirintos da Sabedoria, Lisboa, Temas e Saberes/Círculo de Leitores, 2012, pp. 61-74.

\footnotetext{
${ }^{54}$ Cf. Franco Mollia, "Utopia ierocrática”, loc. cit., pp. 50-54.
} 
SANSONE, Mario, Storia della Letteratura Italiana, Milano, Principato Editore, 1962.

SAPEGNO, Natalino, Compendio di Storia della Letteratura Italiana. Volume: Cinquecento, Seicento, Settecento, Firenze, La Nuova Italia Editrice, 1983.

SILVA, Maria de Fátima (Coord.), Utopias e Distopias, Coimbra, Imprensa da Universidade, 2009.

SQUAROTTI, Giorgio Barberi, Literatura Italiana. Linhas-Problemas-Autores, São Paulo, Nova Stella-Istituto Italiano di Cultura-EDUSP, 1989.

TRINDADE, Manuel de Almeida, Tomás Moro. Um Homem para a Eternidade, Aveiro, ed. de autor, ${ }^{2} 1985$.

VEDRINE, Hélène, As Filosofias do Renascimento, Mem Martins, Europa-América, 1974, pp. 93-98.

VIEIRA, Fátima (Org.), Saberes Partilhados. O Lugar da Utopia na Cultura Portuguesa, Vila Nova de Famalicão, Edições Quasi, 2006. 